\title{
FACTORS AFFECTING CONTRACTOR'S BIDDING SUCCESS FOR INTERNATIONAL INFRASTRUCTURE PROJECTS IN AUSTRALIA
}

\author{
Beltrán AZNAR ${ }^{\mathrm{a}}$, Eugenio PELLICER ${ }^{\mathrm{a}}$, Steven DAVIS ${ }^{\mathrm{b}}$, Pablo BALLESTEROS-PÉREZ ${ }^{\mathrm{c}}$ \\ ${ }^{a}$ School of Civil Engineering, Universitat Politècnica de València, Camino de Vera s/n, 46022, Valencia, Spain. \\ ${ }^{b}$ School of Civil and Environmental Engineering, University of New South Wales, Kensington Campus, \\ NSW 2052 Sidney, Australia \\ ${ }^{c}$ School of the Built Environment University of Reading, Whiteknights, \\ Reading RG6 6DF, United Kingdom
}

Received 26 Dec 2016; accepted 03 May 2017

\begin{abstract}
This paper examines the effects of different factors on the success or failure of bids for infrastructure projects in Australia. Logistic regression analysis was used to empirically determine which factors have the largest effect on bidding success. Data was collected from 123 bids submitted by several infrastructure companies with subsidiaries in Australia. The analysis found that having a competitive advantage and a local partner, and also not competing against a local company were the most important factors; as they significantly increase the chances of success. However, four other factors, having relevant expertise, resource availability, a previous relationship with the client, and a previous relationship with consortium members, are 'essential' to be able to compete; as the absence of any of these four factors results in bid failure, although having them is not a guarantee of success. Results of this paper provide valuable information for any company considering the opportunity of entering into Australia's infrastructure market as well as for companies that are already present in that country and are considering whether to bid for a specific project.
\end{abstract}

Keywords: auction, Australia, bid, consortium, contractor, infrastructure project, international project, subsidiary company.

\section{Introduction}

One the most important and recurring decisions made by contractors in the construction industry is whether to bid or not to bid for a new project (Dzeng, Wang 2016). Not bidding for a project that could be won results in losing an opportunity to make profit, improve market position, and strengthen relationships with other stakeholders (Pellicer et al. 2014). On the other hand, bidding for a project that is not likely to be won results in loss of time, money and effort, important resources that could have been used for a better option (Bageis, Fortune 2009). Moreover, continually losing bids could result in a bad reputation (Lin, Chen 2004).

The decision to bid is a process involving multiple objectives as well as many internal and external factors, many more when it involves construction companies trying to get contracts in an international context (Mosley, Bubshait 2016). Therefore, in order to improve the bidding decision, so as to increase the chances of winning more contracts, it is necessary to understand how these factors affect the success of the bid. This is the research problem considered in this paper.
Numerous researchers have studied this topic (e.g., Ahmad, Minkarah 1988; Shash 1993; Chua, Li 2000; Wanous et al. 2000; Egemen, Mohamed 2007; ShokriGhasabeh, Chileshe 2016). However, these researchers did not empirically investigate the link between the factors and the bidding result. Mostly, these studies tried to explain the decision to bid and/or to anticipate the bidding success by: (1) selecting the most important factors using a questionnaire survey; (2) conducting interviews with experts to learn more about the relationship among the factors; or (3) designing models using different techniques. Among these techniques we can find parametric analysis (Wanous et al. 2000), artificial neural network (Wanous et al. 2003), adaptive neuro fuzzy network (Polat et al. 2014), knowledge-based software (Egemen, Mohamed 2007), fuzzy linguistic approach (Lin, Chen 2004), data envelopment analysis (El-Mashaleh 2010), logit models (Oo et al. 2007, 2008), and multiple forms of statistical analyses (Lowe, Parvar 2004; BallesterosPérez et al. 2014, 2015a, 2016a, 2016b) to cite some.

Corresponding author: Eugenio Pellicer

E-mail:pellicer@upv.es 
Likewise, under different jurisdictions, most public international procurement laws and guidelines (e.g. European Union 2004; United Nations 2006; World Bank 2011; EuropeAID 2014) follow one of two main contract awarding approaches, namely: a price-only (lowest price) criterion or weighted multiple criteria (economically most advantageous tender, EMAT according to the European Union terminology, or best value, BV, according to the United States terminology) (Dini et al. 2006; BallesterosPérez et al. 2015b). Generally, the lowest price is recommended when the focus of the project, technical specifications, and bill of quantities are well-defined (Dini et al. 2006) or when the risk of corruption is too high (Shan et al. 2015). On the other hand, a weighted multiple criteria approach is used when the evaluation requires a number of criteria other than price to be considered and balanced in order to ensure best value for money (Scott 2006); these auctions are often called multi-attribute or multidimensional (Ballesteros-Pérez et al. 2015c). The need for weighting and scoring economic criteria or price-related factors (e.g., life-cycle costs, cost of maintenance, or decommission costs) along with technical criteria (e.g., compliance, time, availability, or quality) is because they are part of a mathematical expression that determines (theoretically) the best return on investment of the procurement of goods, works or services for the owner (Asker, Cantillon 2010).

Within this context, this research aims to determine empirically which factors affect contractors' bidding outcomes (success or failure) in a situation where foreign companies bid for jobs in another country. Despite that, this study will be focused in projects from a single country (Australia). It represents one of the few attempts to measure empirically the importance (degree of influence) of different bidding-related factors in the probability of winning a bid, an issue where, as stated above, most research has involved survey questionnaires and interviews, rather than actual market performance.

The goal will be achieved by analyzing 123 auctions of Australian infrastructure projects (awarded by means of a weighted multiple criteria approach) from the perspective of foreign construction companies that are trying to enter or increase their share of the market. The research will be described in several steps. First, the sources of data as well as an explanation of the research method will be provided. Then, the authors will elaborate a short list of factors from the literature review; these factors will be then screened and expanded later using an expert panel. Then, the authors will select the appropriate model to relate the bidding factors to the bidding outcomes, in this case by means of a logistic model. Later, this model will be fed with actual data from the 123 auctions. The results obtained will be analyzed and discussed. Finally, some relevant contributions, limitations and recommendations will be drawn.

\section{Source of data}

Data on one hundred and twenty three (123) auctions corresponding to large infrastructure projects, in which 20 international companies participated, was gathered during 2015. Country of origin, number of employees and annual revenue of these companies are shown in Table 1; the name of these companies is not revealed due to confidentiality reasons. The companies are international construction companies in the following sectors: energy, infrastructure, transport, supply chain and public services. All these companies have an international presence, having revenues of at least 450 million USD per year. Companies like these are continuously trying to access new markets, hence, looking for international opportunities.

Table 1. Characterisation of the participating bidding companies

\begin{tabular}{clcc}
\hline Company & Country & \# Employees & $\begin{array}{c}\text { Revenue } \\
\text { (Millions of USD) }\end{array}$ \\
\hline A & Spain & 30,000 & 7,000 \\
B & USA & 95,000 & 17,400 \\
C & France & 31,000 & 6,600 \\
D & Canada & 61,900 & 16,300 \\
E & France & 120,000 & 34,700 \\
F & Spain & 7,000 & 1,500 \\
G & Greece & 130,000 & 5,300 \\
H & Spain & 74,000 & 10,400 \\
I & New & 5,500 & 3,400 \\
& Zealand & & \\
J & Italy & 3,000 & 450 \\
K & Canada & 4,400 & 10,000 \\
L & Italy & 35,000 & 5,100 \\
M & Japan & 1,500 & 870 \\
N & Japan & 13,000 & 15,300 \\
O & Spain & 26,000 & 4,700 \\
P & USA & 14,000 & 4,900 \\
R & Italy & 35,000 & 5,100 \\
S & France & 83,000 & 7,100 \\
T & USA & 16,000 & 670 \\
U & Germany & 14,000 & 3,600 \\
\hline & & & \\
\hline
\end{tabular}

Australia was one of the preferred target countries for their expansion. The Australian Government has committed to reform the country's infrastructure taking into account the collaboration of private enterprises (Infrastructure Australia 2016), with more than 50 billion USD committed towards enhancing infrastructure across the country from 2013 to 2020 and beyond. The plan considers projects of 20 million USD and above (DIRD 2016). The Australian economy shares many traits with other highly developed economies, such as the US, so it is believed that the conclusions of the present study can be generalized to most developed countries. 


\section{Research method}

The research was carried out through two main stages: (1) theoretical and methodological, and (2) empirical. The first stage was the theoretical and methodological stage, where the authors analyzed the existing bidding literature in order to understand the problem at hand. Furthermore, this exploration allowed making decisions regarding the research design, mainly in order to choose the proper statistics tools to perform the analysis of the auction dataset. The second stage was the empirical analysis of the data. First, the main factors that, according to previous contributions, affect the outcomes of a weighted multiple criteria auction were obtained and summarized in Table 2. Later, an expert panel was used to check these factors. After the data was gathered, the statistical analyses were performed: cross-tabulation and logistic regressions (individual and multi-factor). Finally, the results were examined and discussed, and conclusions drawn.

\subsection{Variables identification}

The first theoretical and methodological stage mostly consisted of compiling the most meaningful factors (variables) in the procurement process that had been identified by previous researchers (analyzed in the following paragraphs). In particular, the factor selection was performed under two assumptions: (1) the factors needed to be measurable quantitatively (or adaptable to a quantitative scale); and (2) the factors should describe the characteristics of a specific auction or a company, not a country.

Proceeding this way, Ahmad and Minkarah (1988) surveyed more than 400 construction contractors in the United States. Investigating the factors influencing the bidding decision they found that the most important factors were the type of project, the type of owner and the availability of subcontractors. Shash (1993) performed a similar study mailing a questionnaire to 300 top contractors in the United Kingdom, identifying the need for work, the number of competitors in the auction, the experience of the bidder, and the difficulty and risk of the project as the four factors that affect the contractor's decision to bid for a project. It is also worth mentioning the contribution of Lowe and Parvar (2004) who gathered information from past bid opportunities from a British contractor and proposed a logistic prediction model. The factors that they included in the analysis were divided into seven categories: opportunities, resources, project relationships, project procedures, project characteristics, risks, and competitive advantage. In a similar direction, Tiong and Alum (1997), as well as Chua and Li (2000), highlighted the importance of competitive advantage as a key factor for winning a bid.

On the other hand, Wanous et al. $(2000,2003)$ performed a questionnaire survey followed by interviews to six expert contractors, dividing 34 factors into positive and negative with respect to the Syrian construction market. Ling et al. (2005) surveyed and interviewed international firms working in China; their results showed that establishing a wholly owned subsidiary, adopting a differentiation strategy by providing a better service, and client satisfaction were the most important positive factors. Egemen and Mohamed (2005, 2007) surveyed 80 contractors from Northern Cyprus and Turkey, identifying the key determining factors and their importance weight for the bid/no bid and the mark-up size decision. They found that the importance of different factors varies greatly according to the contractor size. In a similar study developed in Saudi Arabia, Bageis and Fortune (2009) indicated that the most critical factors are the size and characteristics of the contractor and the type of owner. Enshassi et al. (2010) discovered that financial capability (of contractor and owner), project value, resources availability and stability of the construction industry were the key factors in Palestine.

From another point of view, Watt et al. (2010) carried out a research in order to identify the relative importance of criteria used by the clients to determine the preferred supplier or contractor. Their results indicated that past project performance, technical expertise and cost are the most important criteria in an actual choice of contractor. Jarkas (2013) remarked on the significance of the owner, project size and duration, and experience in the context of Kuwait. Two studies stated the importance of the project type in the bidding decision process: Leśniak and Plebankiewicz (2015) in Poland, and Ye et al. (2014) in China. Moreover, Shokri-Ghasabeh and Chileshe (2016), in their survey of 81 Australian construction companies, indicated that the key factors were the client financial situation, project risk and value, and the number of competitors. On the other hand, the contractor's financial situation, the project duration and the resource availability were not considered important by the participants. This partially contradicts the work of Aje et al. (2016) who stated that resources availability and project value are the key issues to win an auction in Nigeria.

Table 2 summarizes these contributions dealing with bidding success factors. However, all these studies addressed the problem quantitatively by means of questionnaire surveys or interviews. In this paper a quantitative empirical approach is adopted in order to contrast whether those factors really condition (and to what extent) the bidding success. In order to control the scope of the research the focus of this study is limited to international companies bidding for infrastructure projects in Australia.

In Table 2, the variables "Project value" and "Project duration" are continuous, whereas the others are categorical. These variables answered the following questions:

- Subsidiary: Did the company have an office in the state where the bid is being submitted?

- Expertise: Did the company have previous experience in that type of project?

- Client: Did the company have a previous professional relationship with the owner?

- Consortium: Did the company work with the other members of the consortium before? (in this country or elsewhere) 
Table 2. Summary of relevant factors and their sources

\begin{tabular}{|c|c|c|c|c|c|c|c|c|c|c|}
\hline Contribution(s) & Year(s) & A & B & $\mathrm{C}$ & $\mathrm{D}$ & $\mathrm{E}$ & $\mathrm{F}$ & $\mathrm{G}$ & $\mathrm{H}$ & I \\
\hline Ahmad and Minkarah & 1988 & & & & $x$ & & & $x$ & & $x$ \\
\hline Shash & 1993 & & $\times$ & $x$ & & & & & & \\
\hline Tiong and Alum & 1997 & & & & & & $x$ & & & \\
\hline Chua and $\mathrm{Li}$ & 2000 & & & & & & $x$ & & & \\
\hline Wanous et al. & 2000,2003 & $x$ & $x$ & $\times$ & $x$ & & & $x$ & $x$ & $x$ \\
\hline Lowe and Parvar & 2004 & & & & & & $x$ & $x$ & & $x$ \\
\hline Ling et al. & 2005 & $x$ & & & $x$ & & $x$ & & & \\
\hline Egemen and Mohamed & 2005,2007 & $x$ & $x$ & $x$ & & $\times$ & & $x$ & $x$ & $x$ \\
\hline Bageis and Fortune & 2009 & & & & $x$ & & $\times$ & & & \\
\hline Watt et al. & 2010 & & $x$ & & $x$ & & $x$ & & & \\
\hline Enshassi et al. & 2010 & & & $\times$ & $x$ & & & $x$ & & \\
\hline Jarkas & 2013 & & $\times$ & $x$ & $x$ & & & & $x$ & \\
\hline Ye et al. & 2014 & & & & $x$ & & & & & $x$ \\
\hline Leśniak and Plebankiewicz & 2015 & & $x$ & & & & & & & $x$ \\
\hline Shokri-Ghasabeh and Chileshe & 2016 & & & $x$ & $x$ & & & & & $x$ \\
\hline Aje et al. & 2016 & & & $\times$ & & & & $x$ & & \\
\hline
\end{tabular}

Note: A: subsidiary; B: expertise; C: project value; D: client; E: consortium; F: competitive advantage; $\mathrm{G}$ : resources availability; $\mathrm{H}$ : project duration; I: project type.

- Competitive advantage: Was the company specialized in that type of project (i.e., a tunneling project for a company recognized worldwide by its tunneling quality and capability)?

- Resource availability: Did the company have enough human resources and equipment to accomplish the job?

- Project type: What kind of project was it?

\subsection{Expert evaluation}

After the elaboration of Table 2, some members from the bidding departments of the selected contractors with subsidiaries in Australia were interviewed to provide feedback about the validity of the factor selection. Table 3 provides the characterization of the interviewees. These interviews confirmed the factors included in Table 3. However, the interviewees provided two additional factors (variables) to the list: existence of a 'Local partner' and 'Local competitor'. The first (local partner) gauged if the bidding consortium included a local company. The second factor (local competitor) took into account if there was any local company acting as a competitor in the auction. Both variables are, therefore, categorical.

\subsection{Data collection}

With a list of potentially influential factors identified, data was collected from the internal database of 20 companies with subsidiaries in Australia that had been bidding on projects in Australia for up to ten years. These companies allowed full-access to their databases, facilitating easy collection and guaranteeing the quality of the information obtained. This analysis included the complete set of projects bid by these companies during their history in Australia. Furthermore, some data was obtained from Australian official websites such as Infrastructure Australia (2016) and the Department of Infrastructure and Regional Development (2016) to complete other relevant pieces of information.

As stated earlier, a total of 123 auctions were examined: 31 of the auctions were successful and 92 unsuccessful for the international companies who bid for them. This means the selected companies were relatively suc-

Table 3. Characterization of interviewees

\begin{tabular}{llcc}
\hline$\#$ & \multicolumn{1}{c}{ Academic Degree } & $\begin{array}{c}\text { Experience in the company } \\
\text { (years) }\end{array}$ & $\begin{array}{c}\text { Experience in construction } \\
\text { (years) }\end{array}$ \\
\hline 1 & Bachelor in Civil Engineering and MBA & 5 & 12 \\
2 & Bachelor and Diploma in Civil Engineering & 3 & 15 \\
3 & Bachelor in Civil Engineering and Executive MBA & 8 & 14 \\
4 & Bachelor in Civil Engineering and MBA & 4 & 15 \\
5 & Bachelor in Civil Engineering and PMP & 11 & 11 \\
6 & Bachelor and MSc in Civil Engineering & 7 & 11 \\
7 & Bachelor in Law and Bachelor in Arts & 6 & 12 \\
8 & Bachelor and MSc in Civil Engineering and Executive MBA & 19 & 20 \\
\hline
\end{tabular}


cessful ('average' success rate around 25\%) since average companies in the sector have a success rates around $10 \%$ (Weber et al. 2000). For the categorical variables in Table, " 1 " means "yes" to the questions previously stated, whereas "0" means "no". Now that the variables have been identified and the data collected, the next section will describe the statistical analyses performed.

\section{Statistical analysis and discussion of results}

After analyzing the research designs used by previous authors, logistic regression analysis was selected as the most appropriate for this research. Logistic regression analysis is used in diverse fields such as medicine, social sciences, economics and also engineering (Harrell 2001). Generally, this technique is used for predicting the probability of failure (or alternatively success) of a given process, system, product or phenomenon. Particularly, logistic regression allows the possibility of providing an efficient study of the relation between the factors (independent variables) and the bid outcome (dependent variable), considering that the independent variables can be a mixture of continuous and categorical variables, that they might not be nicely distributed, and that the dependent variable itself is also categorical (Harrell 2001). For a logistic regression, the predicted dependent variable is a function of the probability that a particular subject will be in one of two different categories, in this case: successful bid (contract awarded) or unsuccessful bid (contract not awarded) (Lowe, Parvar 2004).

Other alternative models could have been used, for example the Probit model is another suitable alternative as most factors will be treated as binary variables. Differences between logit and probit models are generally marginal and mostly consist of their different link functions (the logistic model has marginally flatter tails, that is, the probit curve approaches the 0 and $1 \mathrm{Y}$-axis probability values slightly more quickly). On this occasion, however, logistic has been chosen over probit as the former allows for an easier interpretation (logistic regression, unlike probit, can be interpreted as modeling log odds).

Concerning the data structure, despite there seeming to be no agreement yet concerning the minimum number of Events Per Variable, EPV (in this case 'bidding successes') (Courvoisier et al. 2011), a minimum number of ten EPV is generally adopted in practice to avoid bias in the logistic regression coefficients (Peduzzi 1996; Harrell 2001). This means that when analyzing imbalanced auction datasets like the one used here (because the probability of success is lower that the probability of winning), only logistic regression models with up to three independent variables are expected to provide reliable results. As will be seen later, this will be the case for the best logistic model found in this study.

Data analyses were undertaken using the Statistical Package for the Social Sciences IBM SPSS Statistics 20. In particular, three analyses were used: (1) cross-tabulation (or contingency tables) analyses for each item to provide a deeper understanding of the relation factorsuccess; (2) individual logistic regressions to obtain an overview of the significance of each factor in the success of the auction; and (3) logistic regression analyses combining more than one factor, and using those factors found significant at the individual level. Results of these analyses, as well as the corresponding discussion of these results, are shown in the next sub-sections. Lowe and Parvar (2004) also studied the effect of the factors by analyzing the factors first and developing two logistic regression models of the decision to bid, although they used survey data instead of empirical data.

\subsection{Cross-tabulation analysis}

Cross-tabulation analysis is mainly used with categorical variables, allowing a deeper understanding of the individual relationship factor-outcome that provides the probability of success or failure for every factor. The statistical model that is being applied to analyze the factors is the binary logistic regression: the variables can only be explained as 1 or 0 . Therefore, the continuous variables ("project value" and "project duration") as well as the nominal variable ("project type") have to be transformed to dichotomous. For the continuous variables, the mean for the 123 projects was obtained (873 M USD and 29 months respectively), and the project was categorized as " 0 " if it was below the mean, or " 1 " if it was above the mean. In the case of the variable "project type" the projects were classified as natural resources ("0") if they were water or energy projects, and construction projects ("1") if they were road, rail, hospital, tunnel or building projects.

Table 4 displays the cross-tabulation analysis for the 11 independent variables versus the dependent variable (success). For all of them there are 123 cases, except for the variable "consortium" for which ten projects are considered as missing cases. Due to this, these projects were obviously not analyzed for this factor individually.

On analyzing Table 4, it can be seen that some variables do apparently affect the outcome. Initially, an independent variable has higher chances of being significant if most cases are concentrated in any of the diagonals:

- points $(0,0)$ and $(1,1)$, such in the case of the first nine variables like 'Competitive advantage' and 'Local partner'; or in

- points $(0,1)$ and $(1,0)$, when the variable is formulated as negative (the occurrence of that variable is considered an adverse influence), such as happens with the last two (marked with *): 'Local competitor' and 'Project type'.

Therefore, at a first glance, variables 'Competitive advantage', 'Local partner', 'Local competitor' might significantly condition the success or failure of a bid, whereas others like 'Project value' and 'Subsidiary' might also be moderately relevant. The effect of other variables, at this stage at least, is seemingly not that evident. 
Table 4. Cross tabulation results (0: bid failure, 1: bid success)

\begin{tabular}{|c|c|c|c|c|}
\hline \multirow[b]{2}{*}{ Variable (factor) } & \multirow{2}{*}{ Predicted } & \multicolumn{2}{|c|}{ Observed } & \multirow{2}{*}{$\begin{array}{c}\text { Total } \\
\text { (correct/ } \\
\text { incorrect) }\end{array}$} \\
\hline & & 0 & 1 & \\
\hline \multirow[t]{2}{*}{ Subsidiary } & 0 & 31 & 5 & \multirow{2}{*}{$57 / 66$} \\
\hline & 1 & 61 & 26 & \\
\hline \multirow[t]{2}{*}{ Expertise } & 0 & 29 & 0 & \multirow{2}{*}{$60 / 63$} \\
\hline & 1 & 63 & 31 & \\
\hline \multirow[t]{2}{*}{ Project value } & 0 & 60 & 16 & \multirow{2}{*}{$75 / 48$} \\
\hline & 1 & 32 & 15 & \\
\hline \multirow[t]{2}{*}{ Client relationship } & 0 & 49 & 0 & \multirow{2}{*}{$80 / 43$} \\
\hline & 1 & 43 & 31 & \\
\hline \multirow[t]{2}{*}{ Consortium relationship } & 0 & 44 & 0 & \multirow{2}{*}{$75 / 38$} \\
\hline & 1 & 38 & 31 & \\
\hline \multirow[t]{2}{*}{ Competitive advantage } & 0 & 74 & 9 & \multirow{2}{*}{$96 / 27$} \\
\hline & 1 & 18 & 22 & \\
\hline \multirow[t]{2}{*}{ Resource availability } & 0 & 18 & 0 & \multirow{2}{*}{$49 / 74$} \\
\hline & 1 & 74 & 31 & \\
\hline \multirow[t]{2}{*}{ Project duration } & 0 & 47 & 12 & \multirow{2}{*}{$66 / 57$} \\
\hline & 1 & 45 & 19 & \\
\hline \multirow[t]{2}{*}{ Local partner } & 0 & 63 & 2 & \multirow{2}{*}{92 / 31} \\
\hline & 1 & 29 & 29 & \\
\hline \multirow[t]{2}{*}{ Local competitor } & 0 & 4 & 13 & \multirow{2}{*}{$101 / 22 *$} \\
\hline & 1 & 88 & 18 & \\
\hline \multirow[t]{2}{*}{ Project type } & 0 & 10 & 3 & \multirow{2}{*}{$85 / 38^{*}$} \\
\hline & 1 & 82 & 28 & \\
\hline
\end{tabular}

Note: *Variables with negative correlation. Their number of 'total correct' and 'total incorrect' predictions are reversed versus variables with positive correlation ('total correct' corresponds the sum of the anti-diagonal values $(0,1)$ and $(1,0)$, whereas the 'total incorrect' corresponds to the sum of the diagonal $(0,0)$ and $(1,1)$ values).

\subsection{Individual logistic regressions}

As the first part of the logistic modelling analysis, individual logistic regressions were developed. Table 5 shows the results of regression analysis for each individual factor (independent variable). From all factors only three turned out to be significant individually assuming a level of significance of $5 \%$. These are, in order of significance: having a local partner, competitive advantage (both of which have a positive correlation) and local competitor (with a negative correlation). Note that the significance is testing the null hypothesis that the individual parameter does not add extra predictive value beyond the model that ignores all factors: "always predict failure", which is correct $75 \%$ of the time (because $92 / 123$ bids failed). In fact the three variables mentioned above were the only dichotomous variables that could individually improve the model.

For the consortia with a local partner, $50.0 \%$ were successful (29 out of 58 cases); on the other hand, when there was no local presence only $3.1 \%$ of the projects (2 out of 65 cases) were awarded. Having a competitive advantage seemed to be important, with an $89.1 \%$ of failure (74 out of 83 cases) when there was not. When there was no local competitor, $76.4 \%$ of the projects (13 out of 17
Table 5. Factors (variables) levels of significance

\begin{tabular}{lccc}
\hline \multicolumn{1}{c}{ Variable (factor) } & B & df & Sig. \\
\hline Subsidiary & 0.97 & 1 & 0.070 \\
Expertise & 20.85 & 1 & 0.997 \\
Project Value & 0.56 & 1 & 0.180 \\
Client relationship & 21.23 & 1 & 0.996 \\
Consortium relationship & 37.92 & 1 & 1.000 \\
Competitive advantage & 2.31 & 1 & 0.000 \\
Resource availability & 20.69 & 1 & 0.998 \\
Project duration & 0.50 & 1 & 0.235 \\
Local Partner & 3.45 & 1 & 0.000 \\
Local competitor & -2.77 & 1 & 0.000 \\
Project type & -0.66 & 1 & 0.567 \\
\hline
\end{tabular}

Note: B: regression coefficients (in log-odds units); df: degrees of freedom; Sig.: 2-tailed p-value (significant if $<0.05)$.

cases) were awarded. Furthermore, even though the rest of the factors were not classified as significant, important findings were also obtained from their study (see Table 4): expertise, resource availability, client and consortium relationship were necessary to have the possibility of winning, since $0 \%$ of the awarded projects lacked any of these factors. A subsidiary turned out to be important as well, as only $13.9 \%$ ( 5 out of 36 cases) of the projects where the company had no state subsidiary were successful. The project value, duration and type seemed to have no relationship with the auction outcome.

\subsection{Multi-factor logistic regression}

As the second part of the logistic modelling analysis, some multi-factor logistic regressions were developed. Different combinations of factors were investigated in order to study the interaction between them and with the auction outcome (the dependent variable with two possible outcomes: $1=$ success or $0=$ failure). Oo et al. $(2007$, 2008) tried a similar approach adding different factors to the model in order to study the effect on the decision to bid. The final model obtained implements a combination of the three significant factors: local partner, local competitor and competitive advantage. When combined with other variables to test other model configurations, the statistics for every variable change; for this reason, despite the final three variables being identical to the ones originally found significant, it is important to analyze them and confirm that they are still significant individually (as Table 6 shows below), and as a group (explained later).

In this case the Wald statistic (fourth column) assesses the significance of the best coefficient values (B) found for the logistic regression model. This statistic corresponds to the ratio of the square of $\mathrm{B}$ to the square of the Standard Error (S.E.) and is asymptotically distributed as a chi-square distribution. Table 6 results show that the three independent variables, as well as the constant, 
Table 6. Variables in multi-factor logistic model

\begin{tabular}{lcccccc}
\hline \multicolumn{1}{c}{ Variable (factor) } & B & S.E. & Wald & df & Sig. & Exp(B) \\
\hline Local Partner & 3.61 & 1.08 & 11.18 & 1 & 0.001 & 36.96 \\
Local Competitor & -3.70 & 0.95 & 15.14 & 1 & 0.000 & 0.02 \\
Competitive Advantage & 2.66 & 0.74 & 12.95 & 1 & 0.000 & 14.25 \\
Constant & -2.08 & 1.06 & 3.87 & 1 & 0.049 & 0.12 \\
\hline
\end{tabular}

Note: B: regression coefficients (in log-odds units); S.E.: square errors; Wald: Wald statistic; df: degrees of freedom; Sig.: 2-tailed p-value (significant if $<0.05)$; $\operatorname{Exp}(\mathrm{B})$ : log-odds of success.

were statistically significant (for an alpha of 0.05). Therefore, both having a local partner and having competitive advantage have positive correlation, while having a local competitor has negative correlation. These correlations are expressed in the second column (B) and correspond to the coefficient values for the logistic regression for predicting the dependent variable from each independent variable. They are in log-odds units and the prediction equation of the final model is:

$$
\begin{aligned}
& \log \frac{p}{1-p}=-2.08+3.61 \cdot \text { Local partner }- \\
& 3.70 \cdot \text { Local competitor }+2.66 \cdot \text { Comp.advantage, }
\end{aligned}
$$

where $p$ is the probability of being successful.

These estimates describe the relationship between the independent variables and the dependent variable, where the dependent variable is on a logit scale. These estimates tell the amount of increase (or decrease, if the sign of the coefficient is negative) in the predicted log odds of success $=1$ that would be predicted by a one unit increase (or decrease) in the predictor, holding all other predictors constant. Complementarily, we can also read the increase in the odds of success by looking at the values in column $\operatorname{Exp}(\mathrm{B})$. This way, the odds for bidding success when there is a local partner compared to when there is not increase 36.96 times holding the other variables constant. Similarly, the odds for bidding success when there is a local competitor versus when there is not, decrease by $98 \%$. Finally, the odds increase for having competitive advantage increase by 14.25 times compared to when the bidder does not have a competitive advantage.

On the other hand, the -2 Log likelihood value resulted in a value of 63.712 , which evidence a significantly better fit of the model including these three variables versus the model considering only the intercept ( $p$-val$\mathrm{ue}=0.000)$. Cox and Sneel R2 (0.457) and Nagelkerke R2 (0.676) coefficients account for between $45.7 \%$ and $67.6 \%$ of the variance, which means a moderate to good association between the dependent variable and the independent variables. Estimation terminated at iteration number 7 because parameter estimates changed by less than 0.001 .

Furthermore, the overall (Omnibus) tests of the model coefficients are: 75.169 (chi-square test), 3 degrees of freedom and significance at 0.000 . As the model is predictive of the bid success, the null hypothesis (that the model through the group of independent variables taken together with the constant) does not predict the likelihood of succeeding, can be rejected. In this case, the statistics for the Step, Model and Block are the same because no stepwise logistic regression or blocking has been used. Finally, Table 7 shows how many cases are correctly predicted ( 80 cases are true negatives, that is, observed to be 0 and are correctly predicted to be 0 , whereas 28 cases are true positives, that is, observed to be 1 and correctly predicted to be 1), and how many cases are not correctly predicted ( 3 cases are false negatives, that is, observed to be 0 but predicted to be $1 ; 12$ cases are false positives, that is, predicted to be 1 but observed as 0 ).

\begin{tabular}{|c|c|c|c|}
\hline \multirow[b]{2}{*}{ Predicted $\boldsymbol{\nabla}$} & \multicolumn{2}{|c|}{ Observed } & \multirow{2}{*}{$\begin{array}{c}\text { Total } \\
\text { (correct/incorrect) }\end{array}$} \\
\hline & 0 & 1 & \\
\hline 0 & 80 & 3 & $108 / 15$ \\
\hline 1 & 12 & 28 & $(87.8 \% / 12.2 \%)$ \\
\hline
\end{tabular}

Table 7. Summary of the model predictive power

This gives the overall percent of cases that are correctly predicted by the model $(87.8 \%)$. It is the best overall percentage found so far, better than the ones obtained by every factor in the individual analysis, but in this case with combined factors, which provides the model with a good predictive quality. In addition, this model shows a moderate to good association between the dependent variable and the independent variables. Also, it includes the three statistically significant variables. Therefore the model is accurate in nearly nine out of ten auctions when describing the success in the bidding outcome.

\section{Conclusions}

The decision to bid is one of the most important decisions for a construction firm, especially when starting a business in a new country and preparing those bids is more onerous than at home. Hence, it is important for the company to determine the most appropriate projects for which the firm should submit a bid with a minimum chance of success. This paper aims to facilitate this process by providing an overview of the relationship between individual conditioning factors and the bidding outcome. In addition, it develops a model to support the decision-making process. 
A total of nine factors were selected from the literature review, supplemented with two factors from semistructured interviews with experts. Even though only three of them turned out to be significant for the model (in order of significance: having a local partner, having competitive advantage and not competing against a local competitor), the study of the other factors provided interesting findings.In this sense, statistically non-significant factors like having the required technical expertise, resource availability, knowing the client from previous contracts and having previous relationship with the consortium members turned out to be 'absolutely' necessary in order to succeed in an international auction in Australia (their absence meant a bid failure, but having them does not guarantee success). Likewise, having a subsidiary in the state where the bid was submitted turned out to be almost always necessary, as only $13.9 \%$ of the projects that had no state subsidiary were successful. The project economic value, the project duration and the nature of works (project type), on the other hand, did not have any significant connection with the bid outcome.

Finally, a logistic regression model was proposed that included the three significant variables (local partner, competitive advantage and local competitor), demonstrating an overall prediction accuracy of $87.8 \%$. The results of the investigation are promising, taking into account that no previous quantitative empirical studies of this nature have been made and the limited amount of data available.

The main limitation of this research is that it is based on data from a single country, Australia. Even though 123 projects were analyzed, variables such as project value, duration and type would need additional data and analysis to enable a fair comparison with other factors. Furthermore, in any project, there are a many of variables that cannot be measured numerically. Therefore, more work expanding the data collected, both in number and for other countries, is recommended and will surely extend the initial, but interesting nevertheless, conclusions obtained in this study.

\section{Acknowledgements}

The authors want to acknowledge the key collaboration of the members of the expert panel as well as the construction companies that participated in this research.

\section{Funding}

The authors did not have any funding to proceed with this research.

\section{Disclosure statement}

The authors state that there is no financial, professional or personal interest or benefit arising from the direct applications of their research.

\section{References}

Ahmad, I.; Minkarah, I. 1988. Questionnaire survey on bidding in construction, Journal of Management in Engineering 4(3): 229-243.

https://doi.org/10.1061/(ASCE)9742-597X(1988)4:3(229)

Aje, I. O.; Oladinrin, T. O.; Nwaole, A. N. C. 2016. Factors influencing success rate of contractors in competitive bidding for construction works in South-East, Nigeria, Journal of Construction in Developing Countries 21(1): 19-34. https://doi.org/10.21315/jcdc2016.21.1.2

Asker, J.; Cantillon, E. 2010. Procurement when price and quality matter, The Rand Journal of Economics 41(1): 1-34. https://doi.org/10.1111/j.1756-2171.2009.00088.x

Ballesteros-Pérez, P.; González-Cruz, M. C.; Cañavate-Grimal, A.; Pellicer, E. 2014. Estimating future bidding performance of competitor bidders in capped tenders, Journal of Civil Engineering and Management 20(5): 702-713. https://doi.org/10.3846/13923730.2014.914096

Ballesteros-Pérez, P.; Skitmore, M.; Das, R.; del CampoHitschfeld, M. L. 2015a. Quick abnormal-bid-detection method for construction contract auctions, Journal of Construction Engineering and Management 141(7), 4015010. https://doi.org/10.1061/(ASCE)CO.1943-7862.0000978

Ballesteros-Pérez, P.; Skitmore, M.; Pellicer, E.; González-Cruz, M. C. 2015 b. Scoring rules and abnormally low bids criteria in construction tenders: a taxonomic review, Construction Management and Economics 33(4): 259-278. ttps://doi.org/10.1080/01446193.2015.1059951

Ballesteros-Pérez, P.; del Campo-Hitschfeld, M. L.; MoraMelià, D.; Domínguez, D. 2015c. Modeling bidding competitiveness and position performance in multi-attribute construction auctions, Operations Research Perspectives 2: 24-35. https://doi.org/10.1016/j.orp.2015.02.001

Ballesteros-Pérez, P.; Skitmore, M.; Pellicer, E.; GutiérrezBahamondes, J. H. 2016a. Improving the estimation of probability of bidder participation in procurement auctions, International Journal of Project Management 34(2): 158-172. https://doi.org/10.1016/j.ijproman.2015.11.001

Ballesteros-Pérez, P.; Skitmore, M.; Pellicer, E.; Zhang, X. 2016b. Scoring rules and competitive behavior in bestvalue construction auctions, Journal of Construction Engineering and Management 142(9), 04016035. https://doi.org/10.1061/(ASCE)CO.1943-7862.0001144

Bageis, A. S.; Fortune, C. 2009. Factors affecting the bid/no bid decision in the Saudi Arabian construction contractors, Construction Management and Economics 27(1): 53-71. https://doi.org/10.1080/01446190802596220

Chua, D. K. H.; Li, D. 2000. Key factors in bid reasoning model, Journal of Construction Engineering and Management 126(5): 349-357. https://doi.org/10.1061/(ASCE)07339364(2000)126:5(349)

Courvoisier, D. S.; Combescure, C.; Agoritsas, T.; GayetAgeron, A.; Perneger, T. V. 2011. Performance of logistic regression modeling: beyond the number of events per variable, the role of data structure, Journal of Clinial Epidemiology 64(9): 993-1000.

https://doi.org/10.1016/j.jclinepi.2010.11.012

Dini, F.; Pacini, R.; Valletti, T. 2006. Scoring rules, in N. Dimitri, G. Piga, G. Spagnolo (Eds.). Handbook of procurement. Cambridge University Press. https://doi.org/10.1017/CBO9780511492556.013

DIRD. 2016. National infrastructure construction schedule. Australian Government, Department of Infrastructure and Regional Development (DIRD) [online], [cited 1 Aug 2016]. Available from Internet: https://www.nics.gov.au/ project 
Dzeng, R.; Wang, P. 2016. Educational games on procurement and negotiation: Perspectives of learning effectiveness and game strategies, Journal of Professional Issues in Engineering Education and Practice 142(3), 04016004. https://doi.org/10.1061/(ASCE)EI.1943-5541.0000280

Egemen, M.; Mohamed, A. N. 2005. Different approaches of clients and consultants to contractors' qualification and selection, Journal of Civil Engineering and Management 11(4): 267-276. https://doi.org/10.1080/13923730.2005.9636357

Egemen, M.; Mohamed, A. N. 2007. A framework for contractors to reach strategically correct bid/no bid and mark-up size decisions, Building and Environment 42(3): 13731385. https://doi.org/10.1016/j.buildenv.2005.11.016

El-Mashaleh, M. S. 2010. Decision to bid or not to bid: a data envelopment analysis approach, Canadian Journal of Civil Engineering 37(1): 37-44. https://doi.org/10.1139/L09-119

Enshassi, A.; Mohamed, S.; El Karriri, A. 2010. Factors affecting the bid/no bid decision in the Palestinian construction industry, Journal of Financial Management of Property and Construction 15(2): 118-142. https://doi.org/10.1108/13664381011063421

European Union. 2004. Directive 2004/18/EC of the European Parliament and of the Council of 31 March 2004 on the Coordination of Procedures for the Award of Public Works Contracts, Public Supply Contracts and Public Service Contracts.

EuropeAID. 2014. Practical guide to contract procedures for EU external actions [online], [cited 1 Aug 2016]. Available from Internet: http://bit.ly/1MhDHfI

Harrell, F. E. 2001. Regression modeling strategies with applications to linear models, logistic regression, and survival analysis. Springer series in statistics, New York.

Infrastructure Australia. 2016. Australian infrastructure plan. Australian Government, Infrastructure Australia, Canberra.

Jarkas, A. M. 2013. Primary factors influencing bid mark-up size decisions of general contractors in Kuwait, Journal of Financial Management of Property and Construction 18(1): 53-75. https://doi.org/10.1108/13664381311305078

Leśniak, A.; Plebankiewicz, E. 2015. Modeling the decisionmaking process concerning participation in construction bidding, Journal of Management in Engineering 31(2), 04014032. https://doi.org/10.1061/(ASCE)ME.1943-5479.0000237

Lin, C. T.; Chen, Y. T. 2004. Bid/no-bid decision-making-a fuzzy linguistic approach, International Journal of Project Management 22(7): 585-593. https://doi.org/10.1016/j.ijproman.2004.01.005

Ling, F. Y. Y.; Ibbs, C. W.; Cuervo, J. C. 2005. Entry and business strategies used by international architectural, engineering and construction firms in China, Construction Management and Economics 23(5): 509-520. https://doi.org/10.1080/01446190500040141

Lowe, D. J.; Parvar, J. 2004. A logistic regression approach to modelling the contractor's decision to bid, Construction Management and Economics 22(6): 643-653. https://doi.org/10.1080/01446190310001649056

Mosley, J.; Bubshait, A. 2016. Performance evaluation of international contractors in Saudi Arabia, Journal of Professional Issues in Engineering Education and Practice 142(1), 04015007. https://doi.org/10.1061/(ASCE)EI.1943-5541.0000254

Oo, B. L.; Drew, D. S.; Lo, H. P. 2007. Applying a random coefficients logistic model to contractors' decision to bid, Construction Management and Economics 25(4): 387-398. https://doi.org/10.1080/01446190600922552
Oo, B. L.; Drew, D. S.; Lo, H. P. 2008. A comparison of contractors' decision to bid behavior according to different market environments, International Journal of Project Management 26(4): 439-447. https://doi.org/10.1016/j.ijproman.2007.06.001

Peduzzi, P.; Concato, J.; Kemper, E.; Holford, T. R.; Feinstein, A. R. 1996. A simulation study of the number of events per variable in logistic regression analysis, Journal of Clinical Epidemiology 49(12): 1373-1379. https://doi.org/10.1016/S0895-4356(96)00236-3

Pellicer, E.; Yepes, V.; Correa, C. L.; Alarcón, L. F. 2014. A model for systematic innovation in construction companies, Journal of Construction Engineering and Management 140(4), B4014001-1/8. https://doi.org/10.1061/(ASCE)CO.1943-7862.0000700

Polat, G.; Bingol, B.; Uysalol, E. 2014. Modeling bid/no bid decision using Adaptive Neuro Fuzzy Inference System (ANFIS): A case study, in Construction Research Congress, 2014, 1083-1092. https://doi.org/10.1061/9780784413517.111

Scott, S. 2006. Best-value procurement methods for highway construction projects.Transportation Research Board, No. 561.

Shan, M.; Chan, A.; Le, Y.; Xia, B.; Hu, Y. 2015. Measuring corruption in public construction projects in China, Journal of Professional Issues in Engineering Education and Practice 141(4), 05015001. https://doi.org/10.1061/(ASCE)EI.1943-5541.0000241

Shash, A. A. 1993. Factors considered in tendering decisions by top UK contractors, Construction Management and Economics 11(2): 111-118. https://doi.org/10.1080/01446199300000004

Shokri-Ghasabeh, M.; Chileshe, N. 2016. Critical factors influencing the bid/no bid decision in the Australian construction industry, Construction Innovation 16(2): 127-157. https://doi.org/10.1108/CI-04-2015-0021

Tiong, R. L. K.; Alum, J. 1997. Distinctive winning elements in BOT tender, Engineering, Construction and Architectural Management 4(2): 83-94. https://doi.org/10.1108/eb021041

United Nations. 2006. United Nations procurement practitioner's handbook [online], [cited 1 Aug 2016]. Available from Internet: http://bit.ly/1dOcWn6.

Wanous, M.; Boussabaine, A. H.; Lewis, J. 2000. To bid or not to bid: A parametric solution, Construction Management and Economics 18(4): 457-466.

https://doi.org/10.1080/01446190050024879

Wanous, M.; Boussabaine, A. H.; Lewis, J. 2003. A neural network bid/no bid model: the case for contractors in Syria, Construction Management and Economics 21(7): 737744. https://doi.org/10.1080/0144619032000093323

Watt, D. J.; Kayis, B.; Willey, K. 2010. The relative importance of tender evaluation and contractor selection criteria, International Journal of Project Management 28(1): 51-60. https://doi.org/10.1016/j.ijproman.2009.04.003

Weber, F.; Dalluege, C. A.; Shamsi, T.; Franco, M. 2000. Improving bid preparation in supply chains in the construction industry, Journal of e-Business Strategy Management, February/March, 183-193.

World Bank. 2011. Guidelines for procurement of goods, works, and non-consulting services [online], [cited 1 Aug 2016]. Available from Internet: http://www.worldbank.org.

Ye, K.; Shen, L.; Xia, B.; Li, B. 2014. Key attributes underpinning different markup decision between public and private projects: A China study, International Journal of Project Management 32(3): 461-472. https://doi.org/10.1016/j. ijproman.2013.06.001 
Beltrán AZNAR. Got a BSc and MSc in Civil Engineering from the School of Civil Engineering, Universitat Politècnica de València, Spain. He developed part of this studies in the Technische Universitat Wien (Austria) and the University of New South Wales (Australia). He has been working in Australia for a Spanish construction company during a year. Now, he works in another construction company in Europe as well as in Africa.

Eugenio PELLICER. Received his MSc degree from Stanford University, USA, and his PhD degree from the Universitat Politècnica de València, Spain, where he is currently the Dean of the School of Civil Engineering. He is a senior lecturer in project management, being his research interests: innovation in the construction process and project delivery strategies in construction. He has participated in quite a few international projects with other European and Latin-American universities.

Steven DAVIS. Is a Lecturer in the School of Civil and Environmental Engineering, University of New South Wales, Australia. He teaches engineering economics, financial management and project risk management. His research interests include the use of virtual reality in construction visualization, optimal staffing levels in variable workflow situations and risk modeling in construction projects, among others.

Pablo BALLESTEROS-PÉREZ. Holds a PhD in Engineering Projects and Innovation and a MSc in Project Management, both at Universitat Politècnica de València, Spain. After graduating in Civil Engineering and Geological Engineering he has been working as construction tendering manager for ten years in an international private company devoted to DBO of waste water treatment plants. $\mathrm{He}$ is an IPMA certified Project Manager (level C, Full Member of the Association of Project Management (APM) in the UK) and currently is a Lecturer at the School of Construction Management and Engineering. University of Reading, United Kingdom. His areas of interest are project management in general and quantitative bidding in particular. 